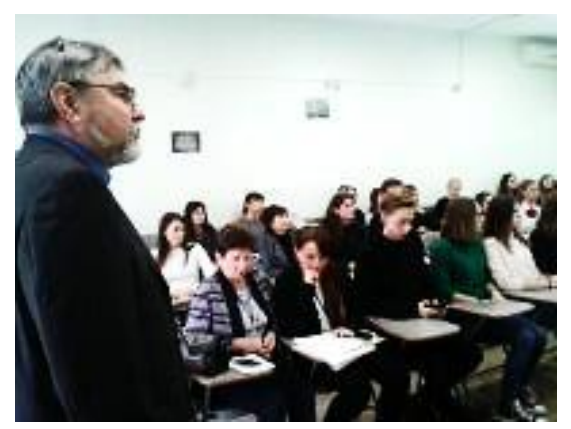

Научный руководитель МБОУ СОШ № 24 - Игнатович Владлен Константинович, доцент, к.П.н., преподаватель Кубанского государственного университета.

Взаимодействие школьников и студентов, совместное освоение ими различных социокультурных практик, таких как, например, научное исследование, в современном мире становятся важным ресурсом их личностного и профессионального самоопределения. Одной из форм такого взаимодействия выступает совместная научнопрактическая конференция, где и школьники, и студенты предъявляют результаты своих исследований и становятся участниками их обсуждения. В этом номере нашего журнала мы знакомим читателей с результатами такой научнопрактической конференции старшеклассников и студентов КубГУ, состоявшейся 19 ноября 2019 года на ФППК КубГУ.

\title{
Исследовательская работа
}

\section{Мохин Кирилл Сергеевич}

Ученик 11 класса, СОШ № 24

Краснодар, Россия

Научный руководитель:

\section{Игнатович Владлен Константинович,}

доцент, к.п.н., преподаватель

Кубанский государственный университет

Краснодар, Россия

Консультант:

Лещенко Марина Владимировна

учитель по курсу «Индивидуальный проект»

e-mail:mvl79@mail.ru

Краснодар, Россия

\section{ВЛИЯНИЕ ГРУППЫ НА ЧЕЛОВЕКА}

Аннотация. В статье дана классификация групп, ее виды и подвиды. Поставлена цель: определить степень влияния группы на мнение человека. Определены задачи: изучить научные теории по проблеме группового влияния, провести эксперимент по определению уровня конформности учащихся 10-х классов, проанализировать полученные данные эксперимента, сделать выводы по результатам исследования. Выдвинуто предположение, что под давлением группы человек может изменить своё мнение. Выделено две формы конформизма: уступчивость и одобрение. Отмечено положительное влияние группы на формирование развитие личности. Показано, как проводилось анкетирование и дебаты. Для того чтобы доказать, что группа способна влиять на мнение человека, проводился эксперимент. В работе показаны результаты, которые могут быть использованы в современной психологии для изучения феномена «конформность», а практически в 
информировании людей, участвовавших в эксперименте, на тему некоторых групповых явлений. Сделан вывод о том, что влияние группы не является однородным, оно не может быть только положительным или только отрицательным, оно зависит от группы и от условий, в которые попал человек.

Ключевые слова: группа, групповое влияние, развитие личности, индивидуализация, конформность, конформизм

Для цитирования: Мохин К.С., Игнатович В.К., Лещенко М. В. Влияние группы на человека. Педагогика: история, перспективы. 2020. Том. 3. № 2. С. 115-124.

DOI: $10.17748 / 2686-9969-2020-3-2-115-124$

\author{
Kirill S. Mohin \\ student 11 "A", secondary school № 24 \\ Krasnodar, Russia \\ e-mail:mvl79@mail.ru \\ Scientific adviser: \\ Vladlen K. Ignatovich \\ Kuban State University \\ Krasnodar, Russia \\ ORCID http://orcid.org/0000-0002-1625-772X \\ e-mail: vign62@mail.Ru

\section{Consultant:} \\ Marina V. Leshchenko \\ teacher on the course "Individual project" \\ Krasnodar, Russia \\ mvl79@mail.ru
}

\title{
HUMAN INFLUENCE
}

Abstract. The article gives a classification of groups, its types and subspecies. The goal is: to determine the degree of influence of the group on human opinion. The tasks are defined: to study scientific theories on the problem of group influence, to conduct an experiment to determine the level of conformity of students in grades 10 , to analyze the experimental data, to draw conclusions based on the results of the study. It has been suggested that under pressure from a group a person can change his mind. Two forms of conformism are distinguished: compliance and approval. The positive influence of the group on the formation of personality development is noted. It shows how surveys and debates were conducted. In order to prove that the group is able to influence the opinion of a person, an experiment was conducted. The work shows the results that can be used in modern psychology to study the phenomenon of "conformity", and practically in informing the people who participated in the experiment, on the topic of some group phenomena. It is concluded that the influence of the group is not homogeneous, it cannot be only positive or only negative, it depends on the group and on the conditions in which the person fell. 
Keywords: group, group influence, personality development, individualization, conformity, conformism

For citation: Mokhin K.S., Ignatovich V.K., Leshchenko M.V. Human influence. Pedagogy: history, prospects. 2020. Vol. 3. № 2. P. 115-124.

DOI: 10.17748/2686-9969-2020-3-2-115-124. (In Russ., abstr. in Engl.).

\section{Введение.}

Человек живёт в обществе и зачастую ему приходится делать выбор, на который хотят повлиять окружающие. Для того чтобы не поддаться группе нужно уметь сопротивляться её давлению. В этом и заключается актуальность нашего проекта. По мнению Л.В. Быкасовой, для неконфликтного существования в мире человека необходимо научить бороться с возникающей агрессией, исходящей из средств массовой информации, микро- и макросоциума [1 Быкасова Л.В. Преемтсвенность в совреемнном педагогическом образовании. Педеагогика: вчера, сегодня, завтра. 2018. Том. 1 №1, с. 12 - 13].

объект исследования: малая группа.

Предмет исследования: конформность.

Цель: определить степень влияния группы на мнение человека.

\section{Задачи:}

1. Изучить научные теории по проблеме группового влияния.

2. Провести эксперимент по определению уровня конформности учащихся 10х классов.

3. Проанализировать полученные данные эксперимента.

4. Сделать выводы по результатам исследования.

Мы предполагаем, что под давлением группы человек может изменить своё мнение.

\section{Методы исследования:}

Анализ и обобщение научной литературы, анкетирование, эксперимент.

Теоретическая значимость исследовательской работы заключается в том, что её результаты могут использовать в современной психологии для изучения феномена «конформность». А практическая - в информировании людей, участвовавших в эксперименте, на тему некоторых групповых явлений.

\section{ЛИЧНОСТЬ В ГРУППЕ}

\section{Классификация групп}

Группа оказывает значительное влияние на психологию и поведение человека. Она представляет собой сложно устроенное общество, в котором люди объединены общими признаком, деятельностью, обстоятельством. Группу разделяют на два вида: условные и реальные. Обособление людей по какому-либо признаку называется условной группой (люди больные гриппом). Реальные ещё два вида: 
лабораторные и естественные. Лабораторные группы создаются с целью проведения какого-либо научного исследования, проверки гипотезы. Естественные ещё на два вида: большие и малые. Большие группы делят на стихийные и устойчивые. Стихийные большие групп кратковременно существующие общности (толпа, аудитория, публика). Устойчивые большие группы - общности, которые сложились в ходе исторического развития общества и занимают определённое место в системе отношений (государство, этнические группы (нации), профессиональные и половозрастные группы). Людей в малой группе объединяет общая социальная деятельность, они находятся в повседневном личностном общении. Малую группу выделяет и обособляет психологическая и поведенческая общность людей. Она разделяется на несколько типов: первичные и вторичные, формальные и неформальные, референтные, группы членства и антиреферентные. Деление на первичные и вторичные было предложено для описания первичной группы, куда относятся семья, группа друзей, группа ближайших соседей.

Затем был выведен признак, позволявший определить характеристику первичной группы - непосредственность контактов. Вторичные же те, где нет непосредственных контактов, общение совершается через посредника. Второе деление малых групп - деление на формальные и неформальные. В формальной группе позиции членов чётко заданы и предписаны групповыми нормами, распределены роли всех членов группы. Неформальная группа возникает стихийно, в ней отсутствуют предписанные статусы и роли, система отношений по вертикали. Третья классификация - референтные и нереферентные. Группы, в которые человек не включён реально, но нормы поведения которых принимает, называются референтными. Нереферентной группой считается малая группа, психология и поведение которой не совсем понятны человеку. Существуют и антиреферентные группы, психология и поведение которых человек не принимает и осуждает.

\section{Положительное влияние группы}

Человек - социальное существо, он постоянно находится под влиянием каких-либо групп. Можно принять тот факт, что человек как личность есть результат многочисленных остаточных групповых влияний, что почти всё в его психологии и поведении складывается и закрепляется под влиянием участия в деятельности больших и малых группах. Положительное влияние группы на формирование развитие личности состоит в следующем:

1. В группе индивид встречается с людьми, которые являются для него основным источником духовной культуры.

2. Отношения между людьми, складываются в группах, несут в себе позитивные социальные нормы и ценностные ориентации, которые усваиваются личностью, включенной в систему групповых отношений.

3. Группа является местом, где индивид отрабатывает свои коммуникативные умения навыки.

4. От участников группы индивид получает информацию, позволяющую ему правильно воспринимать и оценивать себя, сохранять и укреплять всё положительное в своей жизни, избавляться от отрицательного и недостатков,

5. Группа снабжает индивида системой положительных эмоциональных подкреплений, необходимых для его развития [2].

Всё это является частью одного процесса - социализации. Она длится всю жизнь, начиная с рождения и заканчивая смертью. Выделяют три сферы социализации: деятельность, общение, самосознание. Все эти способы связаны и проходят в равной мере у каждого человека. 


\section{Отрицательное влияние группы}

О положительном влиянии группы на человека известно на много больше чем об отрицательном. Так было до недавнего времени. Г. Лебон попытался вывести общие законы поведения человека в толпе. Он утверждал, что средний человек в толпе обнаруживает более низкий уровень интеллекта, становится более доверчивым, агрессивным, ожесточённым, нетерпеливым, аморальным. Лебон преувеличил отрицательное влияние толпы, но в его словах была доля правды. Далее этот феномен подтвердили и внимательно исследовали в социально психологии, он получил название «обезличивание» и «деиндивидуализация». Под влиянием толпы в человеке проявляются свойства группы, в которой он находится, а не его собственные. Именно в толпе человек перестаёт быть личностью, он обезличивается. Помимо этого существует такой феномен как конформизм - изменение поведения в результате реального или воображаемого давления группы. Выделено две формы конформизма: уступчивость и одобрение. Если человек склонен соглашаться с мнением группы, то он конформист, если он имеет тенденцию не соглашаться с мнением, то он нонконформист.

Степень подчинения группе человека зависит от ряда факторов:

- возрастные различия;

- трудность решаемой проблемы;

- статус человека в группе;

- характер групповой принадлежности;

- привлекательность группы для индивида;

- наличие и эффективность связи, подтверждающих верность или неверность конформных поступков человека.

Также влияет численность группы и количество групп, оказывающих влияние. Две группы по два три человека оказывают большее влияние, чем групп из шести человек. Если человек сделал предварительное заявление, то публично он от него не откажется. При выраженном конформизме уменьшается чувство индивидуальной ответственности за поступок. Особенно это проявляется в недостаточно зрелых в социальном плане группах [3].

\section{ЭКСПЕРИМЕНТ}

\section{Подготовка к проведению эксперимента}

Для того чтобы доказать, что группа способна влиять на мнение человека, необходимо провести эксперимент. При помощи консультанта и руководителя был придуман и проведён небольшой эксперимент. С начала мы провели анкетирование для того чтобы узнать мнения учеников 10 классов по поводу нескольких вопросов. Перед ними стояли вопросы, не имеющие точного и однозначного ответа. Им было предложено десять вопросов на темы: патриотизм, учёба, дружба, браки, армия, ВИЧ, отношение к пожилым людям, интернет, цели, сквернословие. Тест состоял из двух противоположных высказываний по разные стороны от шкалы и десятибалльной шкалы, слева были высказывания «за», справа «против». К каждому вопросу была десятибалльная шкала ответа. Было опрошено два 10 класса (29 человек). Для дебатов мы разделили людей на 3 группы (Табл. 1.):

1. «За», люди отметившие в анкете от 1 до 3 баллов включительно. тельно.

2. «Нейтральные», люди отметившие в анкете от 4 до 6 баллов включи-

3. «Против», люди отметившие в анкете от 7 до 10 баллов включительно. 
После анкетирования необходимо было провести дебаты. Для них было выбрано по три человека с каждой стороны.

Таблица 1.

\section{Методика для определения индивидуальной позиции школьника}

1. Те, кто критикует происходящее в стране - патриоты

2. Успешная учёба помогает хорошо устроиться в жизни

3. Я яогу предположить, что моим другом может быть человек другой национальности

4. У молодых людей, рано вступающих в брак больше шансов создать крепкую семью

5. Каждый мужчина должен отдать долг своей родине

6. Люди, больные ВИЧ не нужно особое отношение

7. Пожилым людям нужно уступать места в общественном транспорте

8. Мы не должны проводить много времени в сети, а должны жить в реальности

9. Цель всегда оправдывает средства

10. Сквернословие - это плохо

Источник: составлено автором научной статьи

\section{Проведение эксперимента}

После того как данные были проанализированы и были выбраны участники для дискуссий мы были готовы начать эксперимент. Сам эксперимент заключался в том, что две ни о чём не подозревающие команды начинают дискуссию на одну из вышеперечисленных тем. За этой дискуссией наблюдает подговоренный «зал», который должен оказывать давление на одну из команд. В нашем случае давление оказывалось на группу, которая занимала позицию «Против».

В первой дискуссии участвовали три класса 10 «А», 10 «Б - в роли участников, 11 «А» в роле «зала». Команды, состоящие из трех человек, сели друг на против друга. Вопрос, который мы предложили обсудить «Каждый мужчина должен отдать долг своей Родине». Первая сторона высказывает свою позицию. Затем вторая сторона оппонирует ей. После первого круга в действие вступает «зал». Он начинает давить на одну из сторон. После проведения дискуссии участникам было предложено еще раз оценить свое отношение к данной теме по 10-балльной шкале. 
Первый эксперимент дал «плоды» и мы нашли один из типов подчинения. Мнение одного из участников изменилось с 8 до 5 баллов.

Второй эксперимент проходил в 10 «А» классе. В роли участников выступали две команды по три человека. Вопрос, который стоял перед командами «Цель оправдывает средства». Обсуждение темы проходило по правилам дебатов. Подговоренный зал, состоящий из учащихся 10 «А» класса оказывал давления на участников в позиции «против». Также как и в первом случае, по окончании дебатов ребята оценили свое отношение к этой теме по 10-балльной шкале. Этот эксперимент показал нам ещё один тип подчинения группе мнение одного из участников изменилось с 7 до 10 баллов (Табл. 2.).

Таблица 2.

\section{Результаты эксперимента}

\begin{tabular}{|l|l|l|l|l|l|l|l|l|l|}
\hline патриот & учёба & дружба & браки & армия & вич & старики & интернет & цели & маты \\
\hline$>=3=$ & $>=3=$ & $>=3=$ & $>3=$ & $>=3=$ & $>=3=$ & $>=3=$ & $>=3=$ & $>=3=$ & $>=3=$ \\
7 & 11 & 20 & 6 & 9 & 17 & 19 & 15 & 11 & 13 \\
\hline$<=8=$ & $<=8=$ & $<=8=$ & $<8=$ & $<=8=$ & $<=8=$ & $<=8=$ & $<=8=4$ & $\begin{array}{l}<=8= \\
7\end{array}$ & \\
7 & 3 & 3 & 13 & 7 & 2 & 2 & $<=8=$ \\
\hline
\end{tabular}

Источник: составлено автором научной статьи

\section{Заключение}

Группа является неотъемлемой частью жизни человека. Мы должны знать о том, где мы находимся, и как это может на нас повлиять. Прочитав и проанализировав научную литературу Г. Андреевой, Е. Ильина, Р.С. Немова [4, 5, 2], и познакомившись с экспериментами Аша, Милгремма, Шерифа [6, 7], мы начали изучать влияние малой группы и её феномены. Проведя эксперимент, мы обнаружили два феномена, при которых человек принимает мнение группы - конформизм и нонконформизм. В первом эксперименте участвовали 6 испытуемых, трое «за», трое «против». В этом эксперименте нам удалось найти одни из групповых феноменов, часто встречающихся в странах Азии - конформизм. Это явление распространено в Европе и в нашей стране. В России нет индивидуалистов с древних времён.

Во втором эксперименте участвовало тоже 6 испытуемых 3 «за» и 3 «против». В этом эксперименте мы нашли противоположный феномен, более распространённый в Западных и Европейских странах - нонконформизм [8, с. 77]. Проанализировав итоги эксперимента мы выяснилили, что примерно $33 \%$ учеников склонны принимать мнение группы. Зная некоторые особенности, которые могут влиять на этот показатель, мы выяснили, что в нас конформизм закладывается с детства. Мы должны быть «как все» - это менталитет нашей страны. Ещё одним фактором, который мог повлиять на мнение человека - авторитет старшего класса (эксперимент Рис. №1). Человек мог согласиться с мнением старших. 


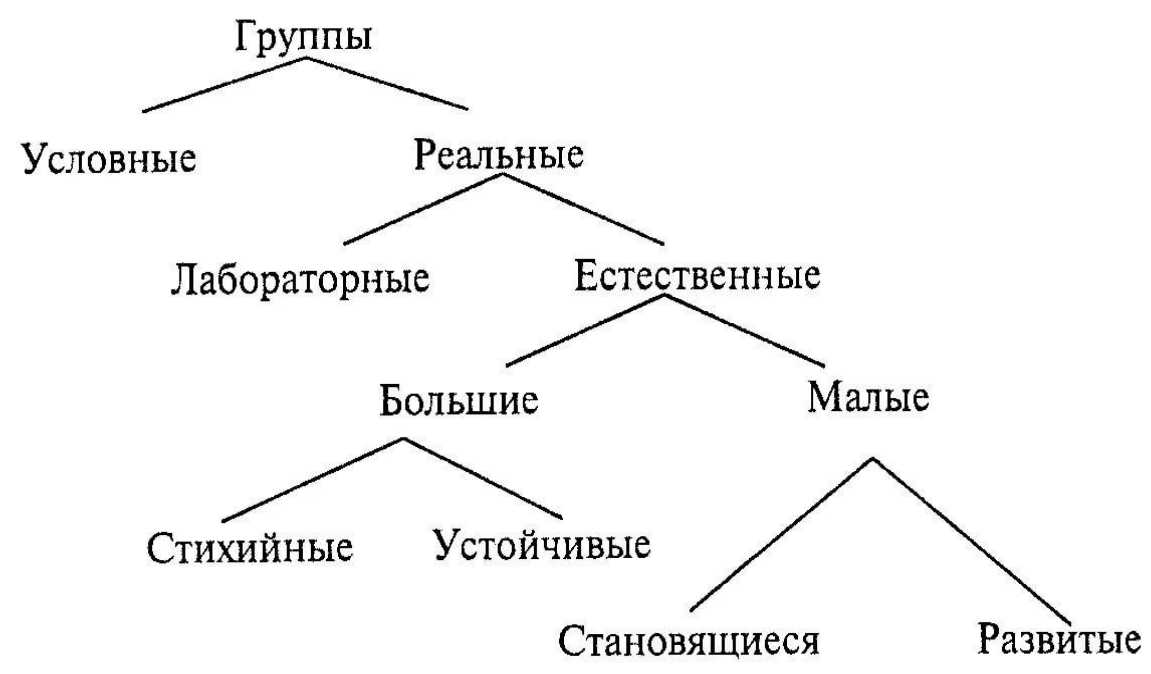

Рис. 1 Классификация групп

Источник: составлено автором научной статьи

Проанализировав всё вышесказанное, мы пришли к выводу, что влияние группы не является однородным, оно не может быть только положительным или только отрицательным, оно зависит от группы и от условий, в которые попал человек.

\section{БИБЛИОГРАФИЧЕСКИЕ ССЫЛКИ}

1. Быкасова Л.В. Преемтсвенность в совреемнном педагогическом образовании. Педеагогика: вчера, сегодня, завтра. 2018. Том. 1. №1. С. 12 - 23. http://dpojournal.ru/index.php/pvsz/article/view/19

2. Немов Р.С. Психология. Учеб. для студентов высш. пед. учеб. заведений. В 2 кн. Кн. 1. Общие основы психологии. - М.: Просвещение: Владос, 1994. - 576 с. - ISBN 5-09-005103-8.

3. Почебут Л.Г., Мейжис И.А. Классификация толпы по Ле Бону https://psyfactor.org/lib/pochebut-03.htm

4. Андреева Г.С. Социальная психология: Учебник для высших учебных заведений / Г.М. Андреева. - 5-е изд., испр. И доп. - М.: Аспект Пресс, 2004. - 365 с.

5. Ильин Е. Психология общения и межличностных отношений. 2-е изд. - СПб.: Питер, 2015. 592 с.: ил. - (Серия «Мастера психологии»).

6. Asch S.E. Effects of group pressure upon the modification and distortion of judgments. Groups, leadership, and men, Harold Guetzdow (ed.). Carnegie Press, 1951.

7. Эффект конформизма: М. Шериф, С. Аш, С. Милграм https://studopedia.ru/11_239421_effekt-sotsialnogo-rasslableniya-ili-lennosti-mringelman.html

8. Годфруа Ж. Что такое психология: В 2-х т. Т. 2: Пер. с франц. - М.: Мир, 1992. 376 с., ил. 


\section{REFERENCES}

1. Bykasova L.V. Succession in modern pedagogical education. Pedagogy: yesterday, today, tomorrow. 2018.Vol. 1. No. 1. P. 12-23. Available at: http://dpojournal.ru/index.php/pvsz/article/view/19

2. Nemov R.S. Psychology. Textbook for students of higher education. ped textbook. institutions. In 2 book Prince 1. General principles of psychology. M.: Education: Vlados, 1994 . 576 p. ISBN 5-09-005103-8.

3. Pochebut L.G., Meijis I.A. Le Bon Crowd Classification. Available at: https://psyfactor.org/lib/pochebut-03.htm

4. Andreeva G.S. Social psychology: Textbook for higher education. G.M. Andreeva. 5th ed., Rev. And add. M.: Aspect Press, 2004. 365 p.

5. Ilyin E. Psychology of communication and interpersonal relations. 2nd ed. St. Petersburg: Peter, 2015. 592 s.: Ill. (Series "Masters of Psychology").

6. Asch S.E. Effects of group pressure upon the modification and distortion of judgments. Groups, leadership, and men, Harold Guetzdow (ed.). Carnegie Press, 1951.

7. The effect of conformism: M. Sheriff, S. Ash, S. Milgram. Available at: https://studopedia.ru/11_239421_effekt-sotsialnogo-rasslableniya-ili-lennosti-mringelman.html

8. Godfroix J. What is psychology: In 2 vols. T. 2: Per. with French. m.: Mir, 1992. 376 p., ill.

Информация об авторе: Мохин Кирилл Сергеевич - учащийся 11 «А» класса МБОУ СОШ № 24

e-mail:mvl79@mail.ru

Руководитель: Игнатович В.К. - к.п.н., доцент, доцент кафедры педагогики и психологии ФГБОУ ВПО КубГУ, Кубанский государственный университет

г. Краснодар, Россия

ORCID http://orcid.org/0000-0002-1625-772X

e-mail:vign62@mail.ru

Консультант: Лещенко Марина Владимировна - учитель по курсу «Индивидуальный проект»

e-mail: mvl79@mail.ru

Поступила: 23.02.2020

После доработки: 21.04.2020

Принята к публикации: 25.04.2020

Автор прочитал и одобрил окончательный вариант рукописи

Information about the author: Mokhin Kirill Sergeevich, student 11 "A" class, MBOU secondary school № 24

e-mail:mvl79@mail.ru

Scientific adviser: Vladlen K. Ignatovich - candidate of pedagogical sciences, associate professor, associate professor of the Department of Pedagogy and Psychology FSBEI HE "Kuban State University" e-mail: vign62@mail.ru 
Consultant: Marina V. Leshchenko - teacher on the course "Individual project" e-mail:mvl79@mail.ru

Krasnodar, Russia

The paper was submitted: 23.02 .2020

Received after reworking: 21.04.2020

Accepted for publication: 25.04.2020

The author have read and approved the final manuscript. 